\title{
O instagram e as hashtags como recurso para a recuperação da informação
}

\author{
Instagram and hashtags as a resource for information retrieval
}

\author{
Thaís Guimarães \\ Universidade Federal Fluminense | Niterói, RJ | Brasil \\ https://orcid.org/0000-0003-1314-345X | thaisgrs@id.uff.br
}

\author{
Dra. Rosa Inês de Novais Cordeiro \\ Universidade Federal Fluminense | Niterói, RJ | Brasil \\ https://orcid.org/0000-0003-1871-4995|rosanovais@id.uff.br
}

Fechas | Recepción: 15/04/2021 | Aceptación: 17/05/2021

\section{Resumo}

Pesquisa exploratória e descritiva que tem como objetivo examinar a natureza das hashtags como um recurso informacional para a nomeação e recuperação da informação do Instagram. O tagueamento é abordado como um processo que é realizado para a nomeação livre de fotos e vídeos pelos usuários mediante o uso de tags (etiquetas) na rede social estudada. O Instagram é compreendido como uma rede social de grande popularidade, que vem sendo cada vez mais aderido pela sociedade como fonte de informação, mas, por outro lado, aponta-se também a questão da desinformação. Apresenta as hashtags como uma forma de gestão de conteúdo, justificando seu uso como uma representação da informação que pode se beneficiar das técnicas de indexação. Utilizam-se como procedimentos metodológicos a pesquisa bibliográfica para levantamento da literatura referente ao tema em bases de dados e a pesquisa empírica que é realizada no ambiente do Instagram a fim da coleta da amostra e objeto de investigação. A abordagem adotada no estudo é quantiqualitativa, em que são examinadas as hashtags de fotos e vídeos empregadas em trinta e três perfis de viagens e turismo, resultando em 330 publicações, entre fotos e

\section{Abstract}

This is an exploratory and descriptive research that aims to examine the nature of hashtags as an informational resource for naming and information retrieval on Instagram. Tagging is addressed as a process that is carried out in order to freely naming photos and videos by users through the use of tags (labels) in the studied social network. Instagram is understood as a social network of great popularity, which has been increasingly adhered to by society as a source of information, but, on the other hand, there it also points out the issue of disinformation. It presents hashtags as a form of content management, justifying its use as a representation of information that can benefit from indexing techniques. Bibliographic research to survey the literature referring to the theme in databases and empirical research carried out in the Instagram environment in order to collect the sample and the object of investigation are used as methodological procedures. The adopted approach in the study is quanti-qualitative, in which photos and videos hashtags used in thirty-three travel and tourism profiles were examined, resulting in 330 publications, including photos and videos, and 945 different hashtags. These are identified and examined according to categories of 
vídeos, e 945 hashtags diferentes. Estas são identificadas e examinadas conforme categorias de análise derivadas da literatura de Ciência da Informação. Os resultados são apresentados estatisticamente e comentados. Concluiu-se que as hashtags cumprem parcialmente a função de meio de busca de informação, mas a relação entre a fonte de informação (fotos e vídeos) e sua nomeação por meio de hashtags intuitivas apresentam problemas: entre outros, inconsistências em relação ao conteúdo. É preciso considerar a possibilidade da criação de orientações para o uso de hashtags no Instagram.

Palavras-chave: hashtags, instagram, tagueamento social, desinformação, viagens e turismo. analysis derived from the Information Science literature. The results are presented statistically and commented. We conclude that hashtags partially fulfill the function of means of searching for information, but the relationship between the source of information (photos and videos) and its naming by means of intuitive hashtags present problems: among others, inconsistencies in relation to the content. The possibility of creating guidelines for the use of Instagram hashtags should be considered.

Keywords: hashtags, instagram, social tagging, disinformation, travels and tourism.

\section{INTRODUÇÃO}

Este artigo é o resultado de estudo que objetiva compreender a natureza das hashtags no ambiente do Instagram. Para tal, no recorte empírico examina-se perfis de viagens e turismo do Instagram, observando a natureza dessas hashtags atribuídas e, se elas podem ser utilizadas como um recurso informal e eficiente de nomeação e recuperação da informação do grande conteúdo dessa rede social. Contudo, sabemos pela literatura e observação do cotidiano de uso da rede social, o desafio que se apresenta na análise da nomeação e busca dessas hashtags que são atribuídas de forma intuitiva pelos usuários (internautas ou participantes), o que não acontece em um serviço de informação como bibliotecas, arquivos, centros de documentação, entre outros, onde esses procedimentos são realizados com as técnicas das áreas, terminologia controlada e ambiente próprio. Ainda, como evolução deste estudo, procuramos trazer à tona a questão da desinformação pelas hashtags.

Os problemas da pesquisa, então, envolvem a compreensão do tagueamento no Instagram como fonte de informação sobre as fotos e os vídeos: queremos observar se é um meio de busca de informação e os possíveis indicativos sobre a prática (comportamento) informacional dos seus usuários na atribuição de hashtags. Para tal, examinam-se os tipos de tags que são atribuídas pelos internautas (participantes) e são a seguir avaliadas, mediante categorias aplicadas na indexação ${ }^{1}$ de assuntos que é realizada por profissionais em serviços de informação.

Em relação aos perfis viagem e turismo selecionados, englobam as companhias aéreas, hotelaria e hospedagem, revistas de viagem, agências de viagem, gastronomia em viagens, intercâmbio e blogs de viagens.

\footnotetext{
${ }^{1} \mathrm{~A}$ indexação é um processo no qual é realizada a condensação e a representação do conteúdo temático de um documento por meio da nomeação de termos provenientes de um controle terminológico. Visa a criação de pontos de acesso para a busca (recuperação) do documento.
} 
Este estudo tem como aporte teórico a área da Ciência da Informação cuja característica marcante é a interdisciplinaridade e sua ligação com a tecnologia da informação. Desde seu surgimento, na década de 1960, passou por diversas mudanças trazendo novos elementos, teorias e subáreas para seus estudos. Segundo Araújo (2018) a Ciência da Informação mudou consideravelmente nos últimos 50 anos. Mesmo que as propostas ainda sejam parecidas com as da época, atualmente existem novas maneiras para realizar o estudo da informação. 0 desenvolvimento das tecnologias facilitou a solução de diversos problemas, ao mesmo tempo que trouxe muitos outros relacionados às questões. A partir desse pensamento, passou-se a observar também como o ser humano produz, faz circular, dissemina, organiza, preserva, usa e se apropria dos registros de conhecimento produzidos, bem como intervém, ao criar instituições, serviços e produtos, nos fluxos informacionais.

Corroborando com este pensamento, Freire (2006) aponta que a perspectiva científica da informação foi uma inovação no campo da produção e comunicação do conhecimento científico, pois trouxe a possibilidade de toda uma criação de tecnologias de informação que se desenvolveram e continuam a evoluir até os nossos dias.

Um dos fatos que impactaram nessa mudança foi a evolução tecnológica. Com o surgimento da Web 2.0, simplificou-se cada vez mais o acesso e a interatividade online através dos links e hipertextos. Baeza-Yates e Ribeiro Neto (2011, pp. 10-11) indicam mudanças fundamentais acontecidas após a enorme propagação da web e os avanços na tecnologia moderna de computadores:

1) os documentos e páginas apresentam a característica de estarem ligados a outros através de hiperlinks;

2) o usuário tem a liberdade para incluir e compartilhar a informação que ele considerou relevante;

3) os avanços em comunicação digital permitem um melhor acesso às redes de trabalho locais e globais. São feitas milhões de consultas diariamente pela web. Assim, as fontes de informação podem ser acessadas rapidamente e desde grandes distâncias;

4) economia em relação ao custo de acesso as diversas fontes de informação;

Somando à evolução tecnológica, aponta Santos (2013) que "os recentes dispositivos de informação e comunicação, a partir de novos padrões de compartilhamento, preservação e disseminação da informação, beneficiam-nos, por meio de suas potencialidades". (p. 94) Atualmente, existe uma facilidade maior para obtenção de informações rotineiras, de lazer e entretenimento, como também para pesquisas técnicas e científicas: "o advento dos computadores e da internet propiciou um acesso extremamente amplo a todo tipo de documentos e registros de conhecimento, do passado e do presente, de todos os lugares do mundo, em tempo real, a partir de diversos dispositivos, inclusive móveis." (Araújo, 2018, p. 44).

Porém, junto a essa facilidade ao acesso também surgiram desvantagens. Uma delas é a questão da confiabilidade e veracidade das informações. Uma forma de garantir a autenticidade é a realização de buscas através de fontes de informação confiáveis. A relação informação e fonte é inerente, se constitui em diferentes suportes e meios, e ferramentas tecnológicas são usadas para a sua recuperação. 
Diante disso, selecionou-se como fontes de informação desta pesquisa as publicações (fotografias e vídeos) nos perfis de viagens e turismo mencionados e as tags relacionadas quando aplicadas no formato de hashtags no Instagram, que é uma rede social que se tornou popular devido à facilidade de compartilhamento de informação através de fotos e vídeos.

Para Brás, Brás e Brás (2016) "a fotografia torna-se um dos meios mais eficazes de conformar as ideias e de influenciar o comportamento gerando saberes com base nas informações contidas em uma única imagem conforme sua data de registro". (p. 113) Ou seja, o conteúdo de uma imagem transmite significados explícitos e implícitos.

A escolha do Instagram como ambiente de estudo se deu pelo fato de que durante a pesquisa bibliográfica, na literatura brasileira da área, percebeu-se que as hashtags no Instagram como recurso para a representação da informação a fim de ser um ponto de acesso para a busca de um registro digital, é um cenário pouco explorado pelos estudiosos da área e, as redes sociais estão cada vez mais presentes no dia a dia de grande parte das pessoas e o Instagram vem se tornando uma grande fonte alternativa de compartilhamento de informações. Logo, recebemos um volume informacional nunca antes visto e cresce a dificuldade de organização desse conteúdo.

Essa dificuldade pode contribuir para a proliferação da desinformação. Para entender a disseminação da informação nessa rede social, é de extrema importância realizar a discussão sobre o conteúdo das hashtags, analisando aspectos que poderão resvalar na veracidade das informações. Então, o estudo poderá também contribuir com a discussão sobre as práticas dos usuários dessa rede social no que tange a nomeação de registros digitais.

\section{FUNDAMENTAÇÃO TEÓRICA}

Para dar base a este estudo, realizou-se a revisão na literatura na área acerca de conceitos, termos, teorias e metodologias que tratam de fontes de informação, fontes de informação na internet, Instagram e desinformação. Por se tratar de uma ferramenta informal e um assunto que se encontra em estado de constante atualização, foi necessária também a busca em blogs e no site do Instagram.

Diversos autores (Le Codiac, 2004; Freire, 2006; Araújo, 2018) são utilizados nos recortes em relação à Ciência da Informação. Freire (2006) lista suas características principais sendo: interdisciplinaridade, ligação com a tecnologia e participação ativa na evolução da sociedade da informação. Araújo (2018) apresenta a trajetória da disciplina e aborda as mudanças que ocorreram em relação aos meios de comunicação devido a evolução tecnologia. Uma das mudanças indicadas se relacionam com a natureza das fontes de informação.

Brás, Brás e Brás situam o uso das imagens e do Instagram como fontes de informação, pois relacionam-se "diretamente com a busca de conhecimento e o processo de pesquisa". Acreditam que "investigar a fotografia como fonte de informação exige do pesquisador a análise de alguns pontos que são relevantes para compreensão da imagem como registro, como instrumento que tem algo a ser narrado. (2016, pp. 114 e 118)

Estes são fatores importantes para os pesquisadores delimitarem as fontes que serão utilizadas e as implicações concernentes. Nesse contexto, insere-se a questão da desinformação que é abordada, entre outros autores, por Karlova e Fisher (2013). As autoras 
apontam o quão problemático pode ser a desinformação e as suas consequências, reforçando assim a necessidade de busca em fontes de informação confiáveis. Delmazo e Valente (2018) e Marwick, et al (2021) também reforçam essa abordagem. No que se refere ao segmento de viagens e turismo, na literatura examinada não foram identificados estudos tocantes a questão da desinformação no segmento mencionado. Contudo, para efeitos deste trabalho, a questão da desinformação nos perfis examinados do Instagram está relacionada com as imprecisões (acidentais ou intencionais) das suas hashtags.

Baeza-Yates e Ribeiro-Neto (2011) ajudam a compreender o universo da web, a evolução tecnológica e os impactos da mesma na organização do conhecimento. De acordo com eles, os sistemas de organização de conhecimento evoluíram consideravelmente desde o surgimento na internet e apareceram diversos novos recursos com este fim.

Neste momento, incluímos aqui a questão da folksonomia, abordada no trabalho como uma forma de introdução para o tagueamento, devido a sua relação com o tema. $O$ autor selecionado para o assunto é o criador do termo folksonomia, Wal (2007). A folksonomia se forma através do conjunto de tags atribuídas pelos próprios usuários da rede, sendo uma atribuição livre e pessoal de tags, muito comum no contexto da web 2.0.

Diferentes autores (Cordeiro, 2018; Cunha, 2018; Marchiori, 2012; Rafferty, 2018; Brandt, 2009) são mencionados para enfatizar o processo do tagueamento, que resulta nas tags. Por meio desses autores é possível ter-se um panorama sobre a sua importância, as vantagens e desvantagens desse processo e quais são as motivações do usuário ao selecionar uma expressão para seu documento.

A partir de entrevista dos criadores da rede ao SXSW (2019) o Instagram, campo de pesquisa deste trabalho, é definido como uma rede social constituída para o compartilhamento de fotos e vídeos. Também são usados o blog do Instagram (2018) e o Statista (2019), este último apresenta estatísticas sobre o uso desta rede social.

Abordando sobre as hashtags, Moura e Mandaji (2014) consideram as hashtags como classificadoras e agrupadoras de informações sobre assuntos afins mediante o uso de palavraschave, ainda, os autores fornecem um ponto de vista atual sobre o tema.

Por fim, para relacionar análise do tagueamento através das hashtags no Instagram, é utilizado o capítulo de Gil Leiva (2012) no qual apresenta alguns princípios da indexação profissional.

\section{O INSTAGRAM E AS HASHTAGS}

O Instagram é uma rede social idealizada para o compartilhamento de fotos, vídeos e mensagens criada em 2010, desenvolvido pelos engenheiros de programação Kevin Systrom e o brasileiro Mike Krieger, acreditando que "postar uma foto era simplesmente o melhor meio para transmitir uma mensagem" (SXSW, 2019)

Ao ser criado, era disponível apenas para a Apple (iOS), e devido à popularidade alcançada, atualmente todos os sistemas operacionais suportam o aplicativo. Para acessar é preciso baixar o aplicativo em seu smartphone e fazer um cadastro do usuário. Os participantes são identificados através de seus nicknames de login.

Systrom (2018), anunciou em junho de 2018 que são cerca de 1 bilhão de usuários ativos por mês, isto é, 1 bilhão de pessoas acessam o aplicativo pelo menos uma vez por mês e segundo o 
Statista (2021) desses 1 bilhão, 500 milhões acessam todos os dias. Em janeiro de 2021 o Brasil contava com o número de 99 milhões de usuários ativos, ficando atrás apenas dos EUA e Índia, que contavam com 140 milhões cada um (Statista, 2021).

Ainda de acordo com o Statista (2021), em janeiro de 2021, desses 99 milhões de brasileiros: $5,8 \%$ tem de 13 a 17 anos; $24,1 \%$ tem de 18 a 24 anos; $31,1 \%$ tem de 25 a 34 anos; $19,8 \%$ tem de 35 a 44 anos; $10,6 \%$ tem de 45 a 54 anos; $5,7 \%$ tem de 55 a 64 anos e 2,9\% tem 65 anos ou mais.

A principal funcionalidade do Instagram - o compartilhamento de fotos e vídeos - é realizada de maneira simples e intuitiva, por isso se torna tão acessível para todas as idades. Depois que a foto ou vídeo é feita (o) ou escolhida (o) em seus arquivos, o usuário pode personalizar a foto ou vídeo com edições dentro do próprio aplicativo e, ao compartilhar, dar uma legenda à mesma. Nesta legenda é possível descrever a imagem e/ou utilizar hashtags para caracterizála. Em seguida, a imagem pode ser compartilhada no próprio Instagram e, à escolha do usuário, em outras redes sociais como Facebook, Twitter, Flickr e Tumblr. Como é uma rede que tem como característica a rapidez e a dinâmica da propagação de informações, o interesse pelo ato de tirar fotos e a instantaneidade na publicação das imagens na rede social, faz com que ela seja cada vez mais popular na sociedade.

Ao seguir (dar follow) e ser seguido por outros usuários, suas publicações aparecem na página inicial do aplicativo. Além disso, é possivel dar follow em hashtags, assim, toda publicação em que a hashtag for utilizada aparecerá no seu feed e o usuário poderá ver publicações do assunto de interesse mesmo que não siga a pessoa que postou.

Existe ainda a aba de "Explorar" que apresenta uma lista de fotos populares para que os usuários possam descobrir novas pessoas a partir de suas publicações e os "stories", onde os internautas publicam fotos ou vídeos que ficam disponíveis durante apenas 24 horas. Assim, o Instagram fornece a possibilidade de o usuário interagir com outras pessoas indicando que gostou, curtindo ou comentando as publicações dos mesmos, e também enviar mensagens privadas para outros usuários.

Cada usuário tem seu perfil que somente ele pode editar e fazer publicações. O perfil é uma página criada no momento do cadastro do usuário na rede, no qual ficarão todas as fotos e os vídeos postados, e no qual também se pode fixar stories nos destaques para que permaneçam mais de 24 horas. Caso prefira mais de privacidade, o usuário pode tornar sua conta privada, e só quem irá ver suas publicações serão seus seguidores e somente pessoas autorizadas pelo dono da conta poderá seguir o perfil.

No Instagram, a representação da informação para a busca, ou seja, atribuição de palavraschave pelo internauta, é feita através de hashtags. Conforme Cunha (2012), as hashtags são "todo conteúdo textual precedido pelo símbolo cerquilha (\#), em inglês hash sign [...] e são criadas livremente pelos membros da rede a fim de adicionar contexto e metadados às postagens, funcionando como palavras-chave" (p. 4). Moura e Mandaji (2014) definem hashtags como aquelas que "classificam, agrupam e direcionam as informações contidas na web sobre os mais variados temas e assuntos, possibilitando maior participação e cooperação dos usuários, através da utilização de palavras-chave para organização" (pp. 6-7) 
A partir dos autores acima citados, entende-se que sobretudo, no Instagram, as hashtags são cadeias de caracteres (apenas letras e números) produzidas livremente pelos usuários - sem nenhuma interferência da plataforma - a fim de adicionar metadados às postagens, funcionando muitas vezes como palavras-chave. A rede não diferencia caracteres maiúsculos de minúsculos e não transforma o termo em hiperlink sem utilizar a cerquilha (\#).

Foram criadas com o objetivo de informar, complementar a descrição da imagem (legendas) e organizar o conhecimento que foi postado. No Instagram, elas têm função de agrupar imagens (fotos e vídeos) relacionadas a um determinado assunto e facilitar a disseminação do mesmo. Quando o usuário clica ou procura uma hashtag, automaticamente é direcionado para uma página onde tem agrupado todas as fotos, vídeos e stories em que a hashtag foi usada.

No site do Instagram, em sua aba "Tirar, editar e compartilhar fotos" existe o link "Como faço para usar hashtags?", ali é explicado passo a passo como utilizar e o que pode ou não pode conter nela.

Nesta rede social, é possível que o usuário da rede busque informações pelas hashtags através do seu mecanismo de busca para que obtenha informações que condizem com as palavraschave procuradas. Para que se tenha um resultado eficaz e haja efetiva recuperação e disseminação da informação das fotos e vídeos, seria indicado que as hashtags atribuídas pelos usuários fossem condizentes com o conteúdo publicado. Caso contrário, muita informação é perdida no ato da busca.

\subsection{As hashtags como representação da informação}

Retomamos aqui a questão da representação da informação, que é realizada em serviços de informação por profissionais, os quais utilizam terminologia controlada para nomeações, a fim de evitar, entre outros aspectos, a ocorrência de alguns fenômenos da linguagem natural, como sinonímia, homonímia, etc., que contribuem para a dispersão e a imprecisão terminológica, conceitual e denominativa, dificultando a comunicação e o entendimento semântico. Situação que não acontece em um ambiente de Instagram, cuja nomeação das publicações é atribuída livremente pelos participantes.

No contexto da organização do conhecimento e representação da informação para além dos serviços de informação, recorre-se as taxonomias, "por sua importância na organização de informações em empresas e instituições, principalmente, no desenvolvimento de portais na ambiente web" (Carlan e Bräscher, 2011, p. 55).

Terra, et al. entendem que

A taxonomia é um sistema para classificar e facilitar o acesso à informação, e que tem como objetivos: representar conceitos através de termos; agilizar a comunicação entre especialistas e entre especialistas e outros públicos; encontrar o consenso; propor formas de controle da diversidade de significação; e oferecer um mapa de área que servirá como guia em processos de conhecimento. É portanto, um vocabulário controlado de uma determinada área do conhecimento, e acima de tudo um instrumento ou elemento de estrutura que permite alocar, recuperar e comunicar informações dentro de um sistema, de maneira lógica. (2005, p. 1) 
Ela apresenta grande importância em questão de recuperação da informação, pois de acordo com Campos e Gomes (2007), "a utilização de taxonomias permite que se estabeleçam padrões de alto nível para a ordenação e classificação de informação através do uso de mecanismos de herança" (p. 2).

Com a interação da web, alguns recursos surgiram dentro do ambiente digital, sendo um deles a folksonomia. Esse termo foi cunhado por Thomas Wander Wal: uma junção do termo "taxonomia" com a palavra "folk" (pessoas). Wal (2007, tradução nossa) explica que a "folksonomia é o resultado da etiquetagem livre e pessoal de informações, realizada em um ambiente digital pelos seus próprios usuários. " Podemos entender então que a reunião das hashtags postadas pelos usuários do Instagram compõem uma folksonomia.

Diferente da taxonomia, ela é conhecida pelo fato de não ter linguagem controlada e assim, as palavras-chave são de linguagem livre à escolha do usuário. Os termos livres atribuídos podem ser quaisquer um que tenham relação com o usuário e o objeto informacional que será etiquetado, de acordo com sua percepção. Nota-se, portanto, que a responsabilidade de etiquetar deixa de ser de um profissional de indexação e passa a ser do próprio da rede, como são feitas nas hashtags anteriormente citadas.

Levando em consideração essa livre escolha do usuário na perspectiva da análise cognitiva, Rafferty (2018, p. 504, tradução nossa) acredita que os sistemas de folksonomia são úteis, porque facilitam a descoberta acidental de informações durante a navegação e permitem rastrear "linhas de desejo" do usuário.

Deste modo, as hashtags se mostram de grande importância em relação à comunicação social na rede. Através delas, os usuários podem encontrar novas publicações e pessoas e elas se tornam uma ferramenta útil para a disseminação e recuperação de diversas informações sem limitações geográficas.

No tagueamento (ato de atribuir tags) são utilizadas palavras-chave que tenham relação com os itens de conteúdo como imagens, textos, arquivos, entre outros. As tags servem como auxílio e complemento para a descrição dos itens e facilitam a busca posterior pelas informações relacionadas, tendo por fim a recuperação da informação. Para Marchiori (2012), além dessa função, "a estrutura das marcações/tags pode apresentar desdobramentos de comportamentos e atitudes de usuários de tais sistemas".

Nos sistemas que utilizam esse recurso, os usuários têm diferentes motivações ao atribuir uma tag. Morrison (2007) realizou uma pesquisa que identifica algumas delas:

1) Encontrá-las em outro momento.

2) Obter mais visibilidade através da marcação inserida.

3) Expressar sua opinião usando uma tag qualificadora (por exemplo: "chato", "legal").

4) Identificar itens de processos de busca que satisfizeram sua demanda.

5) Melhorar a classificação da publicação em questão.

6) Receber benefícios em exercícios lúdicos no ambiente da ferramenta. 
Também nessa linha de pesquisa, Rafferty (2018) e Marchiori (2012) relacionam as razões pelas quais os usuários usam as tags e as categorizam. Abaixo, é possível observar quais são os tipos de tags e quais são as finalidades de cada um:

\section{Tabela 1}

Tipos de tags e suas finalidades

\begin{tabular}{|l|l|}
\hline \multicolumn{1}{|c|}{$\begin{array}{c}\text { TIPOS DE } \\
\text { TAGS }\end{array}$} & \multicolumn{1}{c|}{ FINALIDADES } \\
\hline Conteúdo & $\begin{array}{l}\text { Identificam o conteúdo (“o quê") existentes no objeto que está sendo tagueado. } \\
\text { Exemplo: \#eiffeltower }\end{array}$ \\
\hline Contexto & $\begin{array}{l}\text { Informar o contexto (situação) em que o objeto foi criado, como períodos ou eventos. } \\
\text { Exemplo: \#festivaldecinemadegramado }\end{array}$ \\
\hline Atributo & $\begin{array}{l}\text { Identificar atributos do objeto, características sobre quem ou sobre o assunto que se } \\
\text { trata. Exemplo: \#turismo. }\end{array}$ \\
\hline Propriedade & Esclarecer quem é o proprietário do objeto. Exemplo: \#Thaís. \\
\hline Subjetivas & Para expressar opinião ou emoção do usuário. Exemplo: \#love. \\
\hline Organização & Para organizar informações pessoais e lembrar de tarefas a fazer. Exemplo: \#ToDo \\
\hline Propósito & $\begin{array}{l}\text { Apresentam funções específicas para a tag que não tem relação com o conteúdo do } \\
\text { objeto, como as tags de acessibilidade. Exemplo: \#paracegover. }\end{array}$ \\
\hline Factuais & $\begin{array}{l}\text { Identificam fatos sobre um objeto, como pessoas, lugares ou conceitos. Ajuda a } \\
\text { descrever objetos e também a encontrar objetos relacionados. Exemplo: \#RiodeJaneiro. }\end{array}$ \\
\hline Peferência & $\begin{array}{l}\text { Para organizar um objeto do próprio usuário. Exemplo: \#meucasamento } \\
\text { Exemplo: \#LATAM. }\end{array}$ \\
\hline Funto
\end{tabular}

Fuente: elaborado pelas autoras baseado em Rafferty (2018, p. 503) e Marchiori (2012, p. 52-54).

Dessa forma, é possível perceber que esse recurso vai além de apenas organizar e complementar a informação. Na observação do processo do tagueamento é possível examinar as motivações dos usuários no que tange as atribuições das tags e como isso pode afetar o resultado da busca de outros, seja positivamente ou negativamente.

De acordo com Gil Leiva (2012), entre outros autores, afirma que em um serviço de informação é necessário, entre outros aspectos, que o planejamento, o processo e os resultados da representação da informação na indexação sejam consistentes e haja uma recuperação da informação satisfatória. Para tal, existem categorias que revelam variáveis da qualidade de uma eficiente nomeação de assuntos para a representação e a recuperação (busca) dos registros (fotografias e vídeos). São elas:

1) Exaustividade - diz respeito à quantidade de termos representativos que podem ser atribuídos a um mesmo documento-

2) Especificidade - é referente à exatidão com que os termos representam o conteúdo do registro. Os termos devem ser precisos ao nomear os assuntos, as ideias contidas no registro, e evitando-se termos genéricos. 
A maior exaustividade aumenta os pontos de acesso para busca do registro, mas ocasiona a dispersão conceitual e temática, diminuindo a especificidade conceitual do termo. E viceversa.

3) Correção - é realizada quando há a necessidade de fazer ajustes pela ausência de uma palavra ou por excesso dela na construção de um conceito, assim como quando houver erros de digitação na tag.

4) Consistência - é relativo grau de representatividade dos termos atribuídos para o registro, levando em consideração fatores como a formação do profissional, as características do documento e as condições em que a indexação se realiza.

Essas mesmas categorias da indexação profissional serviram como parâmetro para verificar o tagueamento realizado pelos perfis selecionados no Instagram, pois o estudo procurou observar se as hashtags podem ser usadas como uma forma alternativa ou complementar de representação da informação. Além disso, foi apontada, a questão da desinformação que pode ser gerada através das hashtags.

\subsection{Desinformação}

Apesar de todas as vantagens citadas até o momento, com toda essa evolução tecnológica e grande volume de usuários e informações, também existem desvantagens nesse ambiente virtual. Uma delas é a questão da confiabilidade, pois o ambiente da internet potencializa informações incompletas, desconexas ou inexatas.

Em relação às hashtags, por serem indicações (palavras-chave) atribuídas pelos usuários em linguagem livre, uma preocupação gerada pelo tagueamento é a falta da precisão conceitual e terminológica do registro a ser recuperado. Devido a esse fato, é possível encontrar imprecisões acidentais ou intencionais nos registros dos metadados de conteúdo.

Marwick et al. afirmam que a desinformação

É uma informação falsa ou enganosa que é disseminada intencionalmente com o objetivo de gerar prejuízo, ou para promover objetivos políticos ou ideológicos. [...] Além disso, a forma atual da desinformação está enraizada no enfraquecimento da confiança nas instituições democráticas como a imprensa, o judiciário e os partidos políticos, a economia política da mídia de massa e social e o aumento da influência de comunidades extremistas, conspiratórias e marginais. (2021, tradução nossa)

A desinformação são informações imprecisas e/ou deliberadamente enganosas. Para Karlova e Fisher (2013) a desinformação se difunde facilmente, com o tempo, entre os grupos sociais e é bastante problemática porque pode gerar confusão e desconfiança entre os destinatários e pode dificultar o uso das informações.

Como afirmam Delmazo e Valente, as notícias falsas surgiram há muito tempo, tendo grande visibilidade nos séculos XVI e XVII e, "apesar de as notícias fabricadas serem um fenómeno antigo, a disseminação das redes sociais online e a cultura de partilha abrem margem para que a desinformação atinja um novo patamar." (2018, p. 166). A partir disso precisamos entender que a desinformação no mundo atual assume muitas formas, incluindo imagens, memes, vídeos e as hashtags, por exemplo. 
Os mesmos autores ainda alegam que "a ampliação do consumo de notícias por sites de redes sociais também fomenta um novo tipo de concorrência com os media tradicionais. As fake news [desinformação] se assentam, também, na crise de confiança dos leitores nos veículos tradicionais" (Delmazo e Valente, 2018, p. 159).

Quando as pessoas acreditam em informações enganosas, elas podem influenciar suas ações e decisões. De tal forma que pode ter consequências graves para governos, pessoas, empresas, profissionais da informação e designers de experiência do usuário, bem como para outros grupos sociais.

\section{PROCEDIMENTOS METODOLÓGICOS}

A pesquisa exploratória teve seus procedimentos metodológicos divididos em duas etapas: pesquisa bibliográfica e pesquisa de campo na internet para coleta de amostra. Após, foi realizada o exame das hashtags da amostra de acordo com algumas categorias de análise aplicadas na qualidade da indexação profissional: exaustividade, especificidade, correção e consistência.

$\mathrm{Na}$ relação metodológica do pesquisador com os espaços de estudo na internet, cabe mencionar, a observação de Fragoso, Recuero e Amaral: "A internet constitui uma representação de nossas práticas sociais e demanda novas formas de observação, que requerem que os cientistas sociais voltem a fabricar suas próprias lentes, procurando instrumentos e métodos que viabilizem novas maneiras de enxergar" (2013, pp.13-14).

Para início da pesquisa, foi efetuada busca na literatura da área para seu embasamento teórico. As buscas foram realizadas em diversos site e bases de dados, entre outras, no Portal de Periódicos da Coordenação de Aperfeiçoamento de Pessoal de Nível Superior (Capes), no período de 2018 e 2019.

A busca retornou poucos resultados para artigos que explorassem a técnica de tagueamento em si, pois a maior incidência das pesquisas e artigos abordavam a folksonomia. Escassos resultados também foram obtidos em relação ao Instagram e hashtags, o que foi solucionado ao buscar em fontes informais como blogs e o site do Instagram e também utilizando monografias e dissertações sobre o assunto.

A observação sistemática das hashtags fez-se por meio da análise das hashtags empregadas em perfis de viagens e turismo selecionados da rede social. Essa técnica de coleta de dados nos possibilitou também uma melhor percepção acerca do conhecimento dos usuários sobre essa ferramenta.

Para realizar a análise foram coletadas hashtags nas dez fotos e vídeos mais recentes entre os dias 10/09/2019 e 12/09/2019 nos 33 perfis selecionados na amostra. Resultou-se assim em 330 publicações, entre fotos e vídeos e 945 hashtags diferentes. Durante a coleta, várias delas se repetiram em diversos perfis, formando então o número total da amostra de 1169 hashtags. Portanto, uma média de 35,4 hashtags por perfil.

Com os resultados obtidos foi feito o uso de dados estatísticos para possível análise dos dados, apontando quais tipos de hashtags são mais frequentes nas categorias elencadas para análise. 


\section{RESULTADOS E DISCUSSÃO}

Nesta seção são apresentados e discutidos os resultados relativos aos tipos de hashtags encontrados na amostra mencionada e as categorias de análise derivadas da literatura de Ciência da Informação, no âmbito da representação da informação no que concerne à indexação realizada por profissionais.

Foram encontradas as hashtags que nomeou-se de padrão. "Hashtags padrão" são aquelas que aparecem mais de uma vez no mesmo perfil, em diversas publicações diferentes. Neste trabalho elas foram contabilizadas apenas uma vez, pois os aspectos qualitativos apresentam maior relevância do que os aspectos quantitativos em nossa análise.

As hashtags foram identificadas de acordo com a Tabela 1, e incluiu-se duas novas categorias: tags formadas por aglutinação e tags para publicidade, além das tags que não foram identificadas em nenhuma das categorias por não ter relação com o conteúdo das publicações observadas. No Gráfico 1 é possível observar a quantidade de hashtags, das 945 únicas, coletadas em cada categoria.

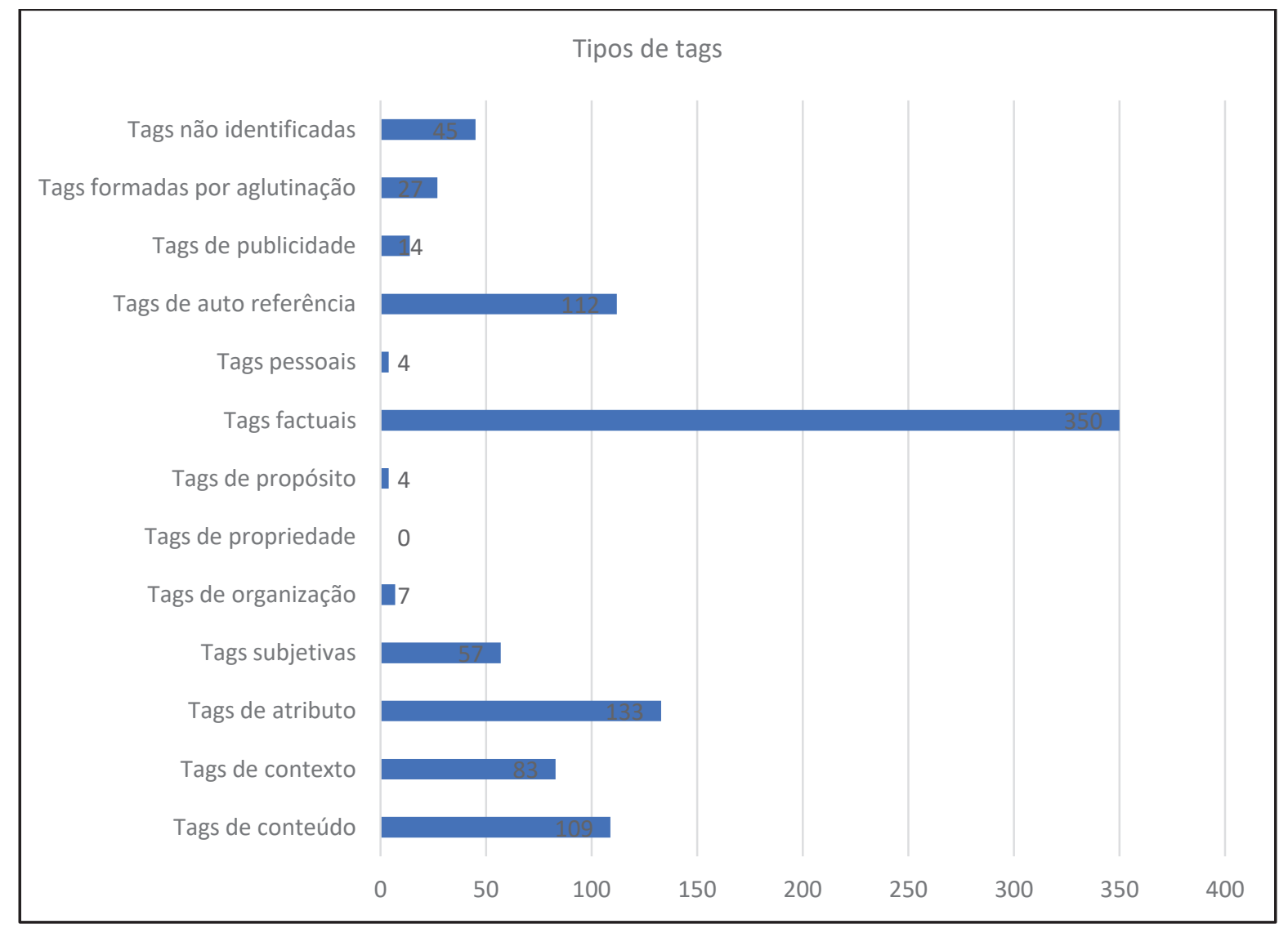

Gráfico 1 - Frequência de cada categoria de hashtags.

Fonte: as autoras (2019).

Podemos observar que as Tags Factuais, que representam lugares e pessoas, são as mais atribuídas. A comunidade de perfis focados em viagens, abrangida na amostra, tem impacto direto nesses números por aplicarem os lugares como palavra-chave em suas publicações. 
Vale ressaltar que muitas vezes uma mesma hashtag foi encontrada em diferentes perfis, completando o total de 1169 da amostragem. As mais repetidas, acima de cinco vezes, podem ser observadas no Gráfico 2.

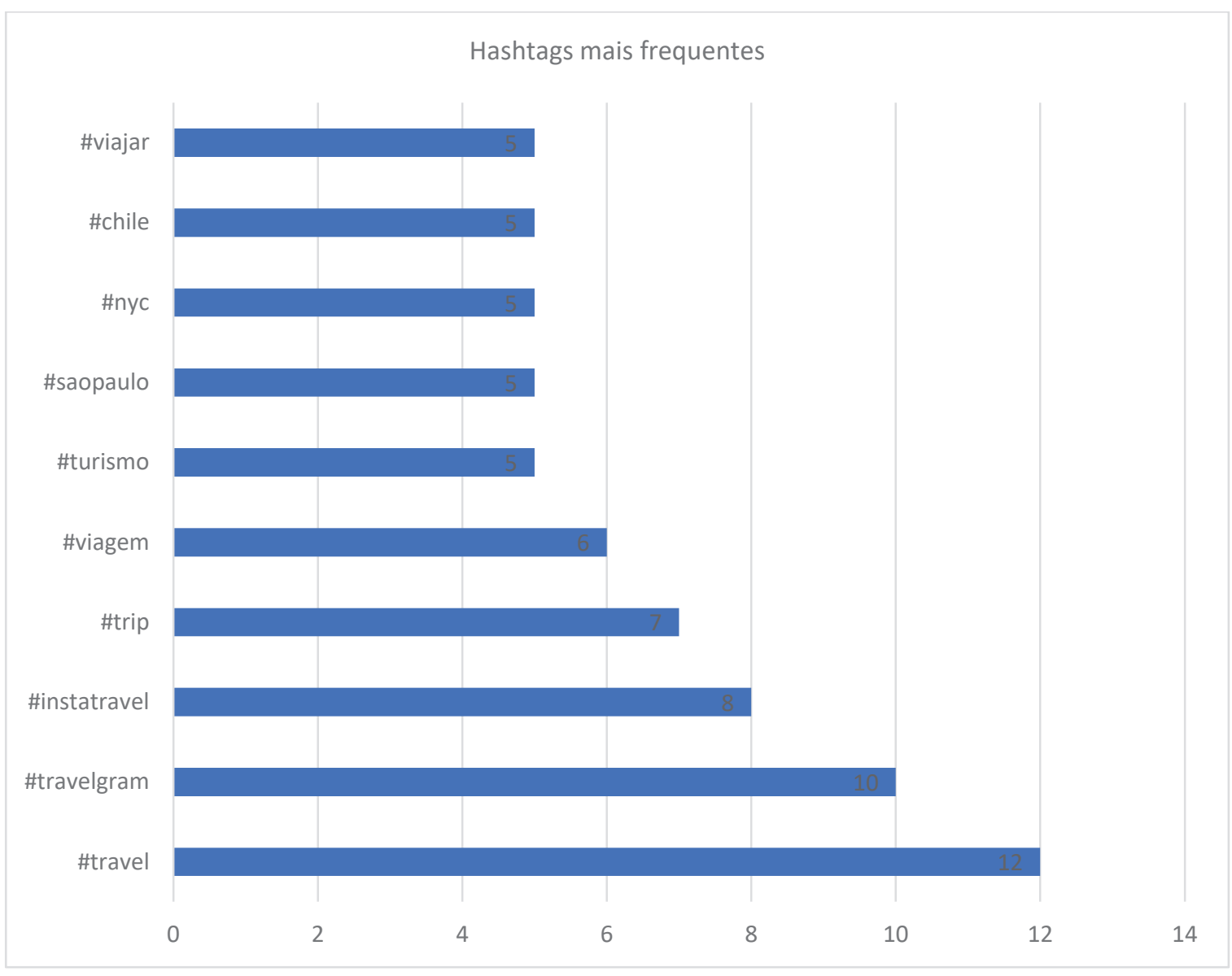

Gráfico 2 - Hashtags em comum mais frequentes entre os perfis Fonte: as autoras (2019).

Observa-se assim, que as hashtags mais frequentes foram usadas 12, 10, 8, 7, 6 e 5 vezes respectivamente.

Ainda que a amostra estudada seja composta apenas por perfis brasileiros, as quatro primeiras hashtags mais frequentes estão em inglês. $O$ inglês é segundo idioma que mais aparece na amostra, sendo 460 hashtags em português, o que representa $48,68 \%$ da amostra e 444 em inglês, que representa $46,68 \%$ da amostra.

O uso frequente do inglês pode ser justificado pelo fato de ser uma língua universal. Através dele a publicação é mais disseminada e visualizada, gerando mais likes e compartilhamentos para o dono do perfil. Dessa forma, são quebradas as barreiras linguísticas enfrentadas por falantes de idiomas menos falados.

Após realizada a coleta dos dados anteriores, elaborou-se a análise das hashtags com base em alguns parâmetros de indexação profissional. Os "elementos que caracterizam tanto o processo quanto o resultado da indexação são a exaustividade, a consistência, a especificidade e a correção" (Gil Leiva, 2012, p. 78). 


\section{a) Exaustividade e Especificidade}

Relembrando, o Instagram permite usar até 30 hashtags por publicação. A média de tags existentes em cada publicação de todos os perfis selecionados na amostra é de 7,6.

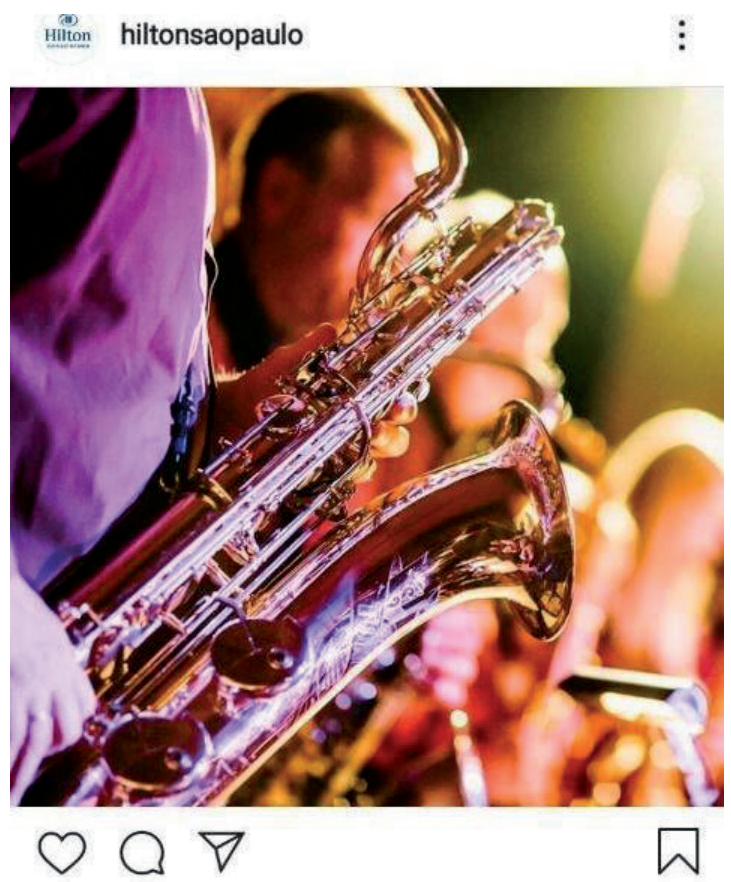

Curtido por treatsandtrips e outras pessoas hiltonsaopaulo Jazz e bons vinhos. Se essa é a sua ideia de uma noite perfeita, seu lugar é no Festival Nederburg Jazz no terraço Armazém Morumbi! Venha curtir a noite de quinta-feira neste evento único. Mais informações: saomo_armazem@hilton.com \#jazz \#jazzmusic \#jazzband \#hiltonsaopaulo \#nederburgjazz \#nederburg \#saopaulo \#saopaulonline \#sp

Figura 1. Exemplo de exaustividade

Fonte: Hotel Hilton. (2019). Disponível em: https://www.instagram.com/p/B1Y3ERPgNvS/

Durante a análise foi notado que quanto mais palavras-chave são incluídas, mais genéricos ficam as hashtags. Confirmando-se a relação entre a alta exaustividade e baixa precisão. Ao atribuir muitas hashtags em uma mesma publicação gera ruído ao realizar a recuperação da informação.

Das hashtags analisadas, os tipos de hashtag que mais apresentaram especificidade foram as tags factuais e de conteúdo, que representam os lugares em que as fotos e os vídeos foram realizados e o conteúdo que existente nelas. A especificidade aparece em $90,5 \%$ e $69,7 \%$ de suas palavras-chave, respectivamente. 


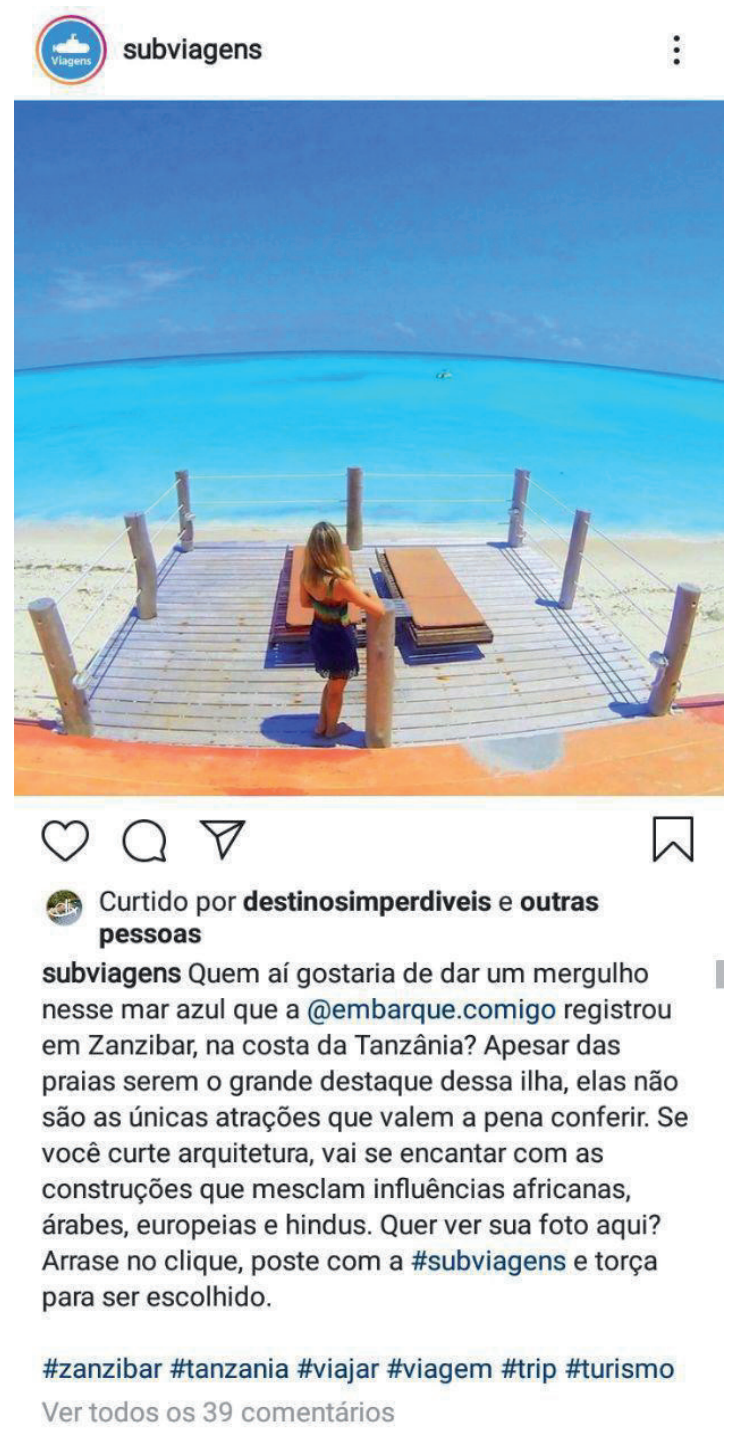

Figura 2. Exemplo de uso de termos específicos e termos genéricos.

Fonte: Submarino Viagens. (2019). Disponível em: https://www.instagram.com/p/B1wrKq9ASGJ/

\section{b) Correção}

A correção da indexação é um indicativo de ausência de dois tipos principais de erros: omissão de termos e inclusão de termos desnecessários. Porém, aqui nós incluiremos também a linguagem usada na internet e a correção dos erros de digitação, que é tido como muito frequente no ambiente digital e se torna uma das desvantagens do tagueamento, questão já abordada na seção 4 .

No Instagram, há o recurso de sugestões de palavras-chave a serem utilizados no momento em que se escolhe uma hashtag, baseado nas mais usadas pelos outros usuários da rede. Isto diminui a quantidade de erros que poderiam ocorrer, então foram encontradas poucas hashtags com este problema.

Esse recurso se mostrou muito eficiente pois das 1169 observadas, apenas seis apresentaram erro de digitação, ou seja $0,5 \%$ da amosta. Elas precisam ser revistas e consertadas para a linguagem correta. As identificadas dentro desse parâmetro foram:

1. \#dulcedeche (Dulce de leche)

2. $\# s s p(S P)$ 
3. \#nambia (Namíbia)

4. \#nambiaafrica (Namíbia África)

5. \#estadosunido (Estados Unidos)

6. \#arquitecture (Architecture)

Além do erro de digitação, a linguagem da internet também é prejudicial para a busca. Por ser relativamente nova ainda é muito excludente, pois apenas o criador e uma parte da comunidade consegue entender o significado de uma palavra específica, se tornando uma desvantagem do taguemento. Na nossa pesquisa foram encontradas palavras-chave nessa linguagem, como por exemplo, \#errejota, \#rildy e \#021 para se referenciar à cidade do Rio de Janeiro. A correção indica ainda que sejam consertados também conteúdos omitidos na nomeação, ou seja, acrescentar a informação.

A correção indica ainda que sejam consertados também conteúdos omitidos na nomeação, ou seja, acrescentar a informação. Foram observados perfis que faziam uso apenas das hashtags padrão, que se mostra muito prejudicial para a divulgação da informação que o objeto passa, pois muitas vezes elas não são específicas ou relevantes, e consequentemente omitem informação importante do objeto.
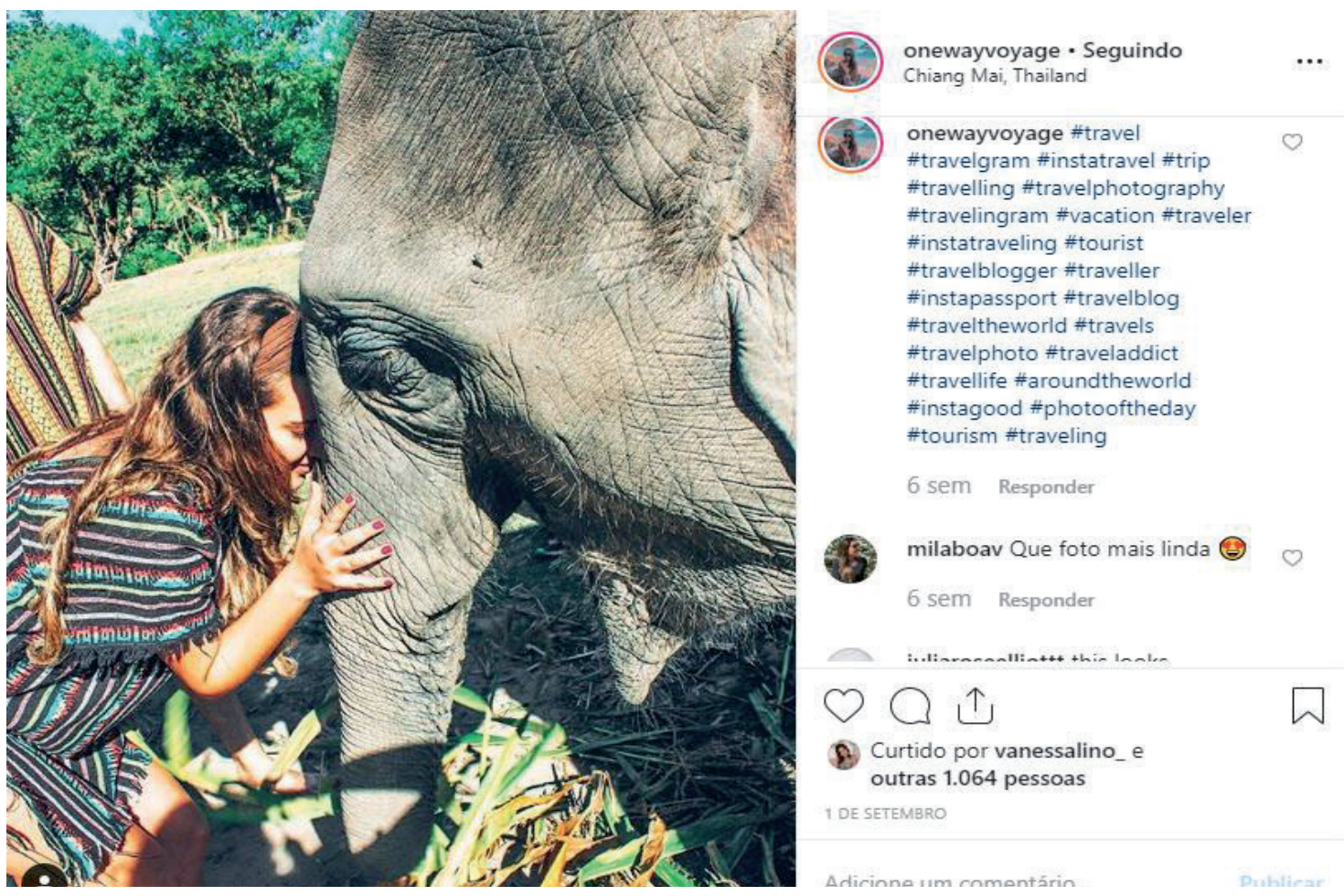

Figura 3. Exemplo de uso de hashtags padrão.

Fonte: One Way Voyage. (2019). https://www.instagram.com/p/B14k8EPI-eX/

A figura 3 exemplifica um perfil que utiliza hashtags padrão, onde inclusive três delas são as mais frequentes na amostra. Nela foram usadas apenas tags gerais de contexto e subjetivas, enquanto poderiam ter sido usadas tags mais específicas sobre o lugar, data ou conteúdo da publicação. Após a correção de palavras-chave omitidas, a publicação ganha mais visibilidade. 


\section{c) Consistência}

Por ser um tagueamento livre em ambiente digital dos usuários, as palavras-chaves podem se moldar ao que for desejado para o conteúdo e para o público de cada postagem específica. Então, em muitos casos foi observada a ausência da consistência em comparação à indexação profissional.

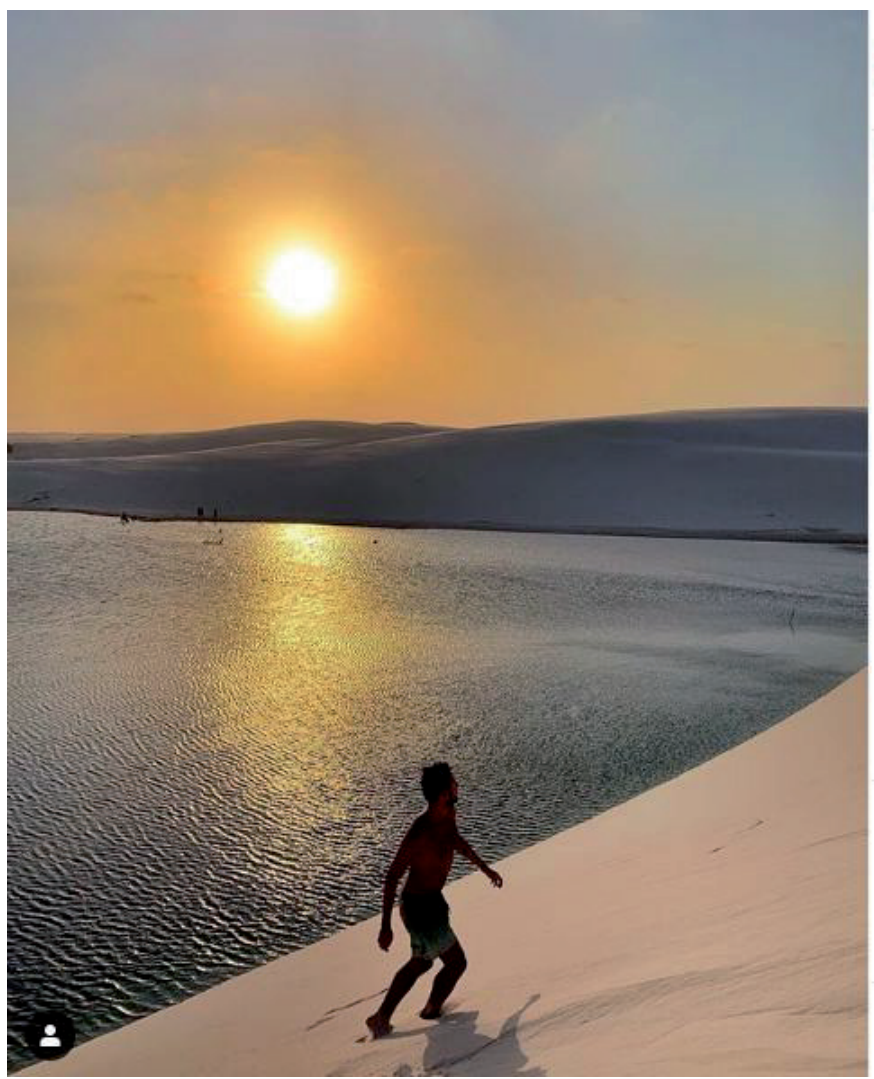

caiotravels - Seguindo Lençóis Maranhenses

caiotravels \#beautifuldestinations \#travelgram \#visitbrazil \#wonderful_places \#euvounajanela \#bestvacations \#vocenooff \#backpacker \#maranhao \#atins \#travelawesome \#nosnatrip \#gopro \#awesomelifestyle \#lencoismaranhenses \#goprobr \#bahia \#dicasdeviagem \#topofbrazil \#destinosesonhos \#gostariadeiroficial \#mochileiros \#santoamaro \#eucurtoonordeste \#mochileros \#bomdia \# achadosdasemana \#brasil \#saoluis

5 sem Responder

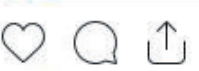

(7) Curtido por findandeat $\mathrm{e}$ outras 7.264 pessoas

3. DE SETEMBRO

Adicione um comentário..

Figura 4. Exemplo de falta de consistência.

Fonte: Caio Travels. (2019). https://www.instagram.com/p/B190I-Op9Wk/

Na figura 4, observamos que apesar da localização da foto ser Lençóis Maranhenses, uma das palavras-chave é \#bahia. Além disso, pode-se notar na figura 4 que existem hashtags que não apresentam especificidade e consistência estritas com a imagem postada.

A inconsistência aparece, então, quando o tagueamento da hashtag no Instagram realizado pelo internauta, faz com que uma mesma fotografia apresente sentidos distantes e até mesmo conflitantes e contraditórios.

Esse fenômeno pode ser explicado pelo motivo das hashtags serem utilizadas também como promoção do conteúdo, ou seja, uma estratégia de uso de hashtags para ampliação de audiências. Assim, quando alguém pesquisa publicações referentes à Bahia, o item acima também será recuperado na busca e consequentemente gerando engajamento para o seu autor.

\section{d) Desinformação}

Devido ao fato do tagueamento ser feito informalmente pelos usuários da rede, sendo de livre escolha de cada pessoa e, talvez, ainda, pelo fato de não existirem orientações para o 
estabelecimento das nomeações na rede, as hashtags se mostram muito vulneráveis à desinformação.

É preciso dar a devida atenção à questão da inconsistência, pois ela pode gerar desinformação como foi visto no exemplo da figura 4. Ao observar a desinformação dentro do segmento de turismo e viagens, essa questão aparece em forma de imprecisão conceitual e terminológica, ou seja, não apresenta clareza sobre o conteúdo publicado. Devido a este fato, além da inconsistência, outro problema foi percebido na aplicação das hashtags padrão, que por não serem específicas podem conter alguma informação que não condiz com a publicação feita. Dessa forma, entende-se que a desinformação também dificulta a especificidade e o acesso rápido a informação deseja.

Vale incluir aqui para pesquisa futura, uma questão constatada por Guess, Nagler e Tucker (2019) quanto ao comportamento informacional e faixa etária no uso de uma rede social. Verificaram que nas últimas eleições americanas, pessoas acima de 65 anos compartilharam sete vezes mais notícias falsas que jovens entre 18 e 29 anos no Facebook. Porém, usuários de qualquer faixa etária não estão isentos de informação falsa, sejam eles "nativos digitais" ou "imigrantes digitais". Soma-se a isso, entre outros fatores, o entendimento pelo usuário quanto à confiabilidade ou não da fonte de informação no ambiente das plataformas de redes sociais digitais.

Na figura 5 existe um exemplo de desinformação, onde a localização é "São Conrado - Rio de Janeiro", mas foram tagueadas \#arpoador, \#ipanema, \#copabana, \#barradatijuca, \#buzios, \#angra, \#paraty e \#arraialdocabo, que claramente não condizem com a publicação e pode ser prejudicial para quem realiza buscas de informações sobre os lugares que estão tagueados.
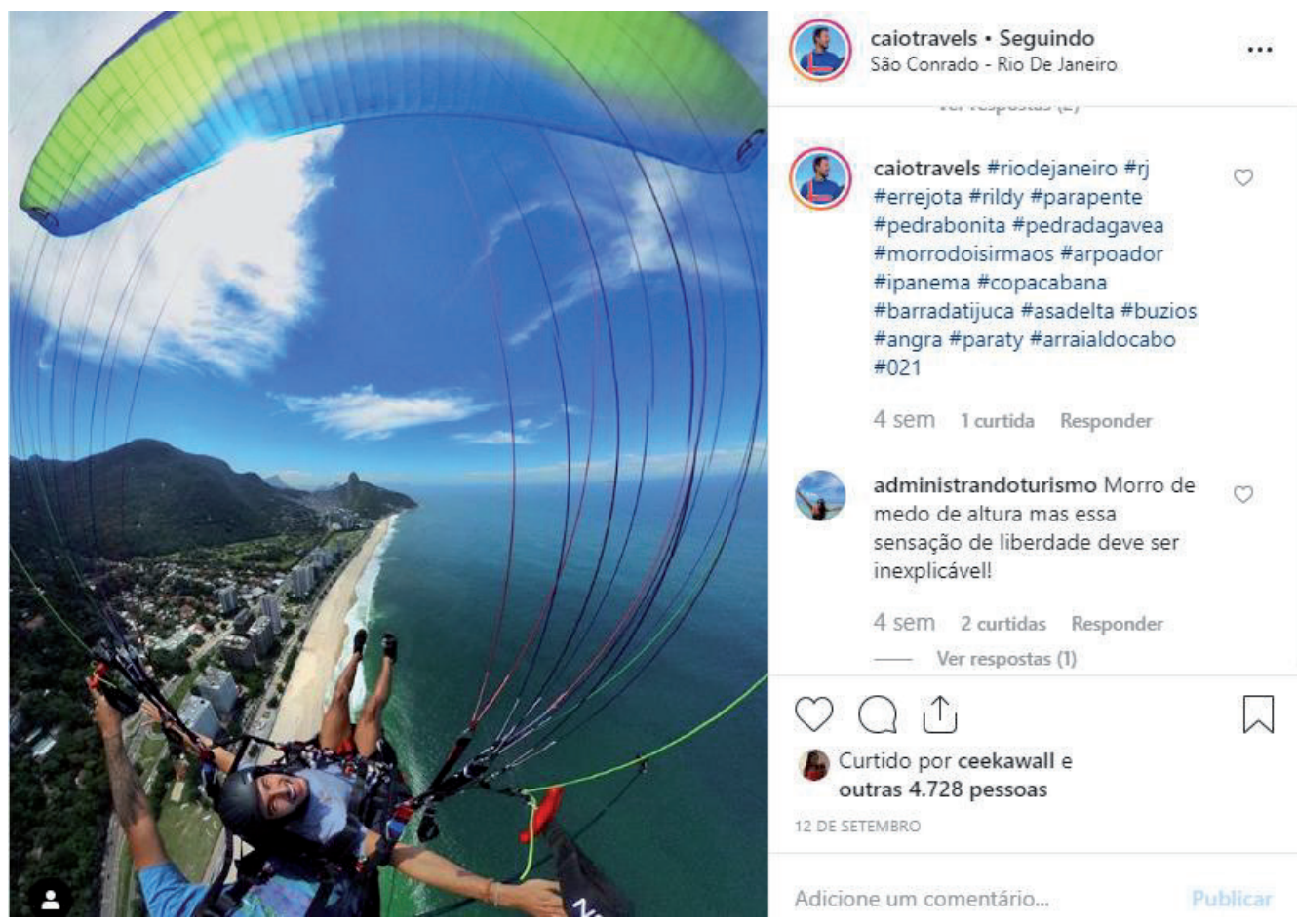

Figura 5. Exemplo de desinformação.

Fonte: Caio Travels. (2019). https://www.instagram.com/p/B190I-Op9Wk/ 
O Instagram apresentou um novo mecanismo, ainda em fase de testes, no qual "publicações que contenham fake news (notícias falsas) terão sua distribuição filtrada da aba Explorar e da pesquisa por hashtags, e exibirão um aviso de que aquele conteúdo é falso." (Fernandes, 2019). Esse recurso pode ter utilidade para os usuários da rede e assim, diminuir o volume de compartilhamento de informações falsas na rede.

\section{CONCLUSÃO}

Foi observado que dentro de um ambiente informal, como a internet, as palavras-chave cumprem parcialmente o papel de representação de imagens. Durante a pesquisa foi possível perceber que o Instagram apresenta problemas de buscas através de tags, pois foram encontradas dificuldades quanto à recuperação das mesmas. Pelo fato de serem tagueadas através da linguagem natural do usuário de acordo com sua percepção e/ou interesse pessoal, a tags podem apresentar diferentes significados e diferentes finalidades para o internauta. Desse modo, foram encontradas inconsistências em relação ao conteúdo da publicação, uso de gírias, linguagem na internet e erros de digitação.

O recurso de sugestões de tags mais frequentes do Instagram se mostrou eficaz para a plataforma dentro do parâmetro de correção, tendo em vista que apenas seis tags foram encontradas com erros de digitação. A exaustividade na amostra evidenciou que quanto maior a quantidade de tags que os perfis usavam mais genéricas e irrelevantes eram indexadas.

Dentro da amostra percebeu-se que as tags mais consistentes e específicas, que consequentemente geravam uma boa recuperação da informação, foram as tags factuais. Assim, observa-se que aproximação existente entre as expressões oriundas do tagueamento com o objeto informacional e as categorias de indexação para a representação de documentos encontra-se na inclusão da informação sobre o lugar em que foi criado o objeto. O perfil da comunidade estudada, que trata de assuntos relacionados a viagens e turismo, pode ter impacto direto nessa análise.

Após análise das tags dentro dos parâmetros de indexação profissional, fica evidente a necessidade da criação de diretrizes para o uso de hashtags do Instagram para que elas possam ser utilizadas como um recurso informal e eficiente de representação e recuperação da informação. Cada tipo de tag apresentou situações diferentes dentro da amostra. Por isso é necessário que, a partir desta política, o usuário consiga identificar qual o melhor tipo de hashtag a ser utilizada de acordo com o conteúdo da publicação que deseja compartilhar.

Em relação a desinformação gerada com a imprecisão, a partir da observação sistêmica da pesquisa de campo na internet percebeu-se que usuários do Instagram usam de forma proposital hashtags que não condizem com o que foi postado, com a intenção de aumentar seu engajamento na rede ou para cunho publicitário, pois ao buscar a tag, a publicação é recuperada por muitos outros usuários. Ainda observando sob o viés da desinformação, a política de indexação também seria interessante para contribuir na diminuição da mesma, pois foi possível perceber que as hashtags são muito vulneráveis.

O mecanismo de defesa contra a desinformação que o Instagram apresenta, apesar de estar em fase de testes, se mostra potencialmente eficaz para o combate às informações falsas. Como o site não interfere na escolha das hashtags feitas pelo usuário, a ferramenta apenas exclui a publicação depois que foi postada. Uma das ferramentas utilizadas para isso é a coleta 
de denúncias de publicações feitas pelos próprios usuários. Então além de uma orientação e um mecanismo de defesa, é necessário educar os usuários da rede para que possam identificar uma informação falsa e todos possam auxiliar no combate.

As limitações apresentadas pelo estudo envolvem o segmento em que foi estudado, viagens e turismo. Pesquisas futuras podem envolver a análise de outros segmentos para maior compreensão do comportamento dos usuários, inclusive examinando-se a variável da faixa etária, além da competência informacional dos participantes, com objetivo de eles se tornarem consumidores de mídia mais bem preparados. Ainda, é necessário realizar em estudo futuro aspectos sobre a política de indexação que são pensadas em termos de política de tagueamento no contexto das plataformas de redes sociais, pois é um tema sobre o qual já são detectadas preocupações na literatura.

\section{Referências}

Araújo, C. A.A. (2018). O que é Ciência da Informação? KMA.

Baeza-Yates, R. \& Ribeiro-Neto, B. (2011). Modern information retrieval. Addison Wesley.

Brandt, M. B. (2009). Etiquetagem e folksonomia: uma análise sob a óptica dos processos de organização e recuperação da informação na web. [Dissertação, Universidade de Brasília]. Repositório Institucional UnB. http://repositorio.unb.br/handle/10482/7057?mode=full

Brás, R. X., Brás, A. X., Brás, A. J. S. (2017). Imagem fotográfica como fonte de informação. Revista Bibliomar, 15(1/2), 113-123. http://hdl.handle.net/20.500.11959/brapci/126466

Campos, M. D. A., Gomes, H. E. (2008). Taxonomia e classificação: o princípio de categorização. DataGramaZero: Revista de Ciência da Informação, 9(4). https://doi.org/10.22478/ufpb.1981-0695.2008v3n2.5281

Carlan, E. \& Bräscher, M. (2011). Sistemas de organização do conhecimento na visão da ciência da informação. Revista Ibero-Americana de Ciência da Informação, 4(2). https://brapci.inf.br/index.php/res/v/72824

Cordeiro, R. I. N. (2018). O delineamento de uma pesquisa em imagens e audiovisuais na Ciência da Informação: o "tagueamento" como quarta dimensão. Informação \& Informação, 23(1), 6-30. http://dx.doi.org/10.5433/1981-8920.2018v23n1p06

Cunha, E. L. T. P. (2012). Etiquetagem de micromensagens no Twitter: uma abordagem linguística. [Dissertação, Universidade Federal de Minas Gerais]. Repositório Institucional UFMG http://hdl.handle.net/1843/ESBF-8UZJ4X

Delmazo, C. \& Valente, J. C. L. (2018). Fake news nas redes sociais online: propagação e reações à desinformação em busca de cliques. Media \& Jornalismo, 18(32), 155-169. https://doi.org/10.14195/2183-5462_32_11

Fernandes, R. (2019, 17 de dezembro). Instagram anuncia ferramenta para combater notícias falsas no Brasil. Techtudo. https://www.techtudo.com.br/noticias/2019/12/instagram-anunciaferramenta-para-combater-noticias-falsas-no-brasil.ghtml

Fragoso, S., Recuero, R., Amaral, A. (2013). Métodos de pesquisa para a internet. Sulinas.

Freire, G. H. (2006). Ciência da informação: temática, histórias e fundamentos. Perspectivas em Ciência da Informação, Belo Horizonte, 11(1), 6-19. http://portaldeperiodicos.eci.ufmg.br/index.php/pci/article/view/442

Gil Leiva, I. (2012). Aspectos conceituais da indexação. Política de indexação. (pp. 31-106). Cultura Acadêmica. 
Guess, A., Nagler, J., Tucker, J. (2019) Less than you think: Prevalence and predictors of fake news dissemination on Facebook. Science Advance. 5(1) eaau4586. https://advances. sciencemag.org /content/5/1/eaau4586/tab-pdf

Hearst, M. A. (1999). The use of categories and clusters for organizing retrieval results. En Tomek Strzalkowski (Ed.), Natural language information retrieval (pp. 333-374). Springer.

Instagram, INC. (2021) Como faço para usar hashtags no Instagram?. Instagram. https://help.instagram.com/351460621611097?helpref=search\&sr=1\&query=hashtags\&search _session_id=ab6083de3a2f780b218308407cb4c245

Karlova, N.A. \& Fisher, K.E. (2013, 14 de março). A social diffusion model of misinformation and disinformation for understanding human information behaviour. Information Research, 18(1) paper 573. http://InformationR.net/ir/18-1/paper573.html

Marchiori, P. Z. Informação e conhecimento nos processos de tagging (marcação) de conteúdo colaborativo. (2012). En Maria Inês Tomael (Org.), Compartilhamento da Informação. (pp. 4172). EDUEL.

Marwick, A., Kuo, R., Cameron, S. J., Weigel, M. (2021). Critical Disinformation Studies: A Syllabus. Center for Information, Technology, \& Public Life (CITAP), University of North Carolina at Chapel Hill. https://citap.unc.edu/critical-disinfo

Morrison, P. J. (2007). Folksonomies: why are they tagging, and why do we want them to?. Bulletin of the American Society for information Science. 34(1) https://doi.org/10.1002/bult.2007.1720340105

Moura, K. F. \& Mandaji, C. D. S. (2014). A relação das hashtags com as palavras de ordem presentes nas manifestações brasileiras de 2013. XV Congresso de Ciências da Comunicação da Região Sul (Intercom Sul). Universidade do Sul de Santa Catarina, Palhoça, Santa Catarina, Brasil.

Rafferty, P. (2018). Tagging. Knowledge Organization, 45(6), 500-516.

Statista. (2021). Distribution of Instagram users in Brazil as of January 2021, by age group. Statista. https://www.statista.com/statistics/866268/instagram-user-share-brazil-age/

Statista. (2021). Eading countries based on number of Instagram users as of April 2019 (in millions). Statista. https://www.statista.com/statistics/578364/ countries-with-most-instagram-users/.

Statista. (2021). Instagram - Statistics \& Facts. Statista. https://www.statista.com/topics/1882 /instagram/

SXSW. (2019, 1 de abril). Keynote: Instagram Founders Kevin Systrom \& Mike Krieger / SXSW 2019. [Vídeo]. Youtube. https://www.youtube.com/watch?v=zc0Wt6WrjUg\&ab_channel=SXSW

Systrom, K. (2018, 20 de junho) Welcome to IGTV. Instagram. https://about.instagram.com/pt$\mathrm{br} / \mathrm{blog} / \mathrm{announcements/welcome-to-igtv}$

Terra, J. C., Schouerl, R., Vogel, M. J., Franco, C. (1998). Taxonomia: elemento fundamental para a gestão do conhecimento. Biblioteca Terra Fórum Consultores. http://paginapessoal.utfpr.edu.br/ mansano/arquivos/taxonomia.pdf/view

Wal, T. V. (2007, 2 de fevereiro). Folksonomy. Vanderwal.net. http://www.vanderwal.net/folksonomy. html

\section{Semblanza de las autoras}

Thaís Guimarães é bibliotecária e aluna de mestrado no Programa de Pós-Graduação em Ciência da Informação, da Universidade Federal Fluminense (PPGCI/UFF). Cursa Arquivologia também pela Universidade Federal Fluminense (UFF). Realiza estudos que envolvem a interdisciplinaridade entre a Ciência da Informação e a Comunicação Social. 
Rosa Inês de Novais Cordeiro é professora titular da Universidade Federal Fluminense (UFF), no Departamento de Ciência da Informação e Programa de Pós-graduação em Ciência da Informação (PPGCI). É doutora em Comunicação e Cultura (UFRJ/1998). Realizou o scholar-inresidence (estágio sênior-CNPq) na University of Illinois at Urbana-Champaign (2010/2011) e o pós-doutorado no Instituto de Psicologia da UFRJ (2003). Mestre em Comunicação (UFRJ/1990). 